\title{
EPRU
}

Economic Policy Research Unit

Institute of Economics

University of Copenhagen

Studiestræde 6

DK-1455 Copenhagen K

DENMARK

Tel: (+45) 35324411

Fax: (+45) 35324444

Web: http://www.econ.ku.dk/epru/

\section{Information, Polarization and Delegation in Democracy}

\author{
Christian Schultz
}

2003-16

ISSN 0908-7745

The activities of EPRU are financed by a grant from The National Research Foundation 


\title{
Information, polarization and delegation in democracy
}

\author{
Christian Schultz ${ }^{12}$
}

November 2003

\footnotetext{
${ }^{1}$ Institute of Economics, University of Copenhagen, Studiestraede 6, DK 1455 Copenhagen K, Denmark. e-mail: cs@econ.ku.dk

${ }^{2}$ Part of the work on this paper was done while I visited CES-ifo in München in the fall 2001. I thank CES-ifo for its hospitality. I also thank the seminar audience at Carlos III, Madrid for very helpful comments.
} 


\begin{abstract}
This paper investigates the merits of different democratic institutions when politics is uni-dimensional, there is uncertainty both about the preferences of the future electorate and the future polarization of political parties, and politicians have better information about the state of the world than voters. Three types of institutions are compared: direct democracy, representative democracy, where politicians are accountable and independent agencies, where they are not. Low uncertainty about the state of the world and the future electorate's preferences and high expected polarization make direct democracy optimal, while the opposite configuration makes representative democracy optimal. Independent agencies are optimal for intermediate values.
\end{abstract}

Keywords: Accountability, redistribution, constitutional design, voting, information, direct democracy

JEL: H1, H7, K4 


\section{Introduction}

The proper degree of governmental accountability has been the subject of a large debate in recent years. Along with the debate many important policy decisions have been removed from the realm of representative democracy: congresses and parliaments. Direct democracy, which has a long history in Switzerland and several US states, has been used recently by several European countries in the process of ratifying the treaties which govern the development of the European Union. In contrast, important policy areas like monetary policy have deliberately been moved from the control of congresses and parliaments into central banks with high autonomy. Witness for instance the creation of the European Central Bank. A similar process has taken place in many other policy areas. Independent agencies take care of regulation of telecoms etc. Alongside with these developments, the possibility of voting through the internet has spurred interest in direct democracy.

Evidently politics concerns many different issues, but as a first approximation we will consider the case where the grand issue, the salient issue is uni-dimensional, and where the important divide among voters and parties is inbetween left and right. Think of the salient issue as redistribution policies, taxation or more generally the size of the welfare state. The paper provides a first takeon the relative advantages and drawbacks from the different governance structures: direct democracy, representative democracy or independent agency.

The analysis focuses on the fundamental trade-off between information and accountability. As Downs (1957) pointed out, the electorate at large has insufficient incentives to become informed about complicated issues in politics, the functioning of the economy etc. Politicians on the other hand are 
briefed by experts and bureaucrats and it is their job to gather information and take decisions. In short there is an asymmetry of information between the electorate and the politicians. This asymmetry of information speaks in favor of delegating decision making from the electorate to elected politicians.

Delegation, however, raises problems of congruence of preferences and of accountability. When voters elect representatives to take political decisions, it is important for them that the politicians have preferences similar to their own. We consider a society with two parties motivated by ideology and power. When parties' ideologies are polarized, voters are faced with a nontrivial choice between left and right. Then the problem of congurence of preferences becomes important. Polarization also influences the implications of accountability, as a left wing government will take over if a right wing government is voted out of office.

The choice of governance structure is a long run decision, written in the constitution. When it is decided, the future is uncertain: The future polarization of parties is unknown, as are the preferences of future electorates. Similarly, the economic conditions and other basic state variables - the state of nature - can not be forecasted with certainty. This multi-dimensional uncertainty is an important feature influencing the constitutional choice.

The paper provides a model where a constitutional stage is followed by two policy periods in which policy is determined through the governance structure chosen at the constitutional stage. At the constitutional stage the degree of polarization of the parties, the exact preferences of future median voters and the future state of nature are all stochastic variables, unknown to the voters, who only know the distributions. After the choice of constitution, voters learn how polarized the parties are. When they cast votes - either on policies as in direct democracy or on parties as in representative democracy, 
they are however still uninformed about the state of nature unlike the politicians as discussed by Downs. We calculate expected utilities for all voters for each of the three modes of governance. As it turns out the ranking of all voters are the same in the model, so it makes sense to speak of a best mode of governance.

Direct democracy has the advantage that the preferences governing the choice of policy is the electorate's, or more precisely the median voter's. The more polarized are the parties the larger is this advantage. For sufficiently high degrees of polarization, direct democracy is the best governance structure for voters. The drawback of direct democracy is that the policy choice is uninformed and that future policies are uncertain if the preferences of the electorate are very uncertain. The more uncertainty about the state of the world and the electorate's preferences, the less attractive is therefore direct democracy. For higher degrees of uncertainty and lower degrees of polarization, the crucial choice is between representative democracy and independent agencies. Both governance structures ensure that the actual choice of the policy is made by an informed party. They differ on whether the politician is held accountable for the choice or not. Under independent agency voters elect a government once and for all in the first period and cannot subsequently vote it out, so the government is not accountable.

Under representative democracy, the governing party is accountable: It will be voted out if the electorate is not satisfied. Voters are prospective, they vote for the party they believe chooses a better policy for them in the following period. Hence they will vote out a right wing party if they believe that the state of the world favors left wing policies. This may occur as the parties are assumed to be ideologically more "stubborn" than the voters in the middle: The median voter is a swing voter. As an example, con- 
sider the case where the uncertainty concerns the cost of the welfare state. If the government sector is actually very efficient and tax distortions are low, the median voter prefers a large welfare state and votes for the leftist party, while she votes right otherwise. This is an advantage of representative democracy. However, this voting behavior also induces a cost to representative democracy. The governing party is interested in reelection. Since it has information, the voters have not, its policy is a signal about the state of the world. It may therefore distort its policy in order to manipulate the beliefs of the electorate and become more popular. Some policy distortion always occurs under representative democracy and it will be towards more extreme policies. A right wing party chooses an even more rightist policy, in order to signal that the state of the world favors right wing policies. We show that high uncertainty about the state of the world tends to make representative democracy a better governance structure than independent agency, since the option value associated with the possibility of choosing another government becomes high. In contrast, high expected polarization of the parties tends to make independent agency better than representative democracy. The reason is that the policy distortion associated with representatives democracy becomes very large when polarization is high.

Clearly, voters receive information from many sources: newspapers, lobbyists, business, organized labor etc. These many and varied sources of information alleviates the asymmetric information problem. Still empirical assessments show that a large fraction of the electorate typically is poorly informed: As Bartels (1996) puts it "The political ignorance of the American voter is one of the best-documented features of contemporary politics ...". It is also true that much of the information in media is cheap talk, that "experts" often contradict each other and that the different interest groups 
provide conflicting information.

The relative virtues of the different modes of governance have been considered before in the literature. Maskin and Tirole (2001) consider a model, where the salient issue is binary. The electorate's preferred policy depends on the state of the world, which is only known by politicians. Politicians do not belong to parties and may or may not have congruent preferences with the electorate at large. If the electorate decides to replace a politician in an election, the preferences of the new politician are chosen at random. So unlike in our framework, the policy space is binary and politicians do not represent parties with known preferences, polarized on a left-right wing dimension. Maskin and Tirole show that the better the electorate is informed about the state of the world, the more attractive is direct democracy. The choice between representative democracy, where the chosen politician can be replaced, and independent agencies ("juridical power" in the language of Maskin and Tirole) depends on how eager the politician is to be reelected. Unlike our analysis this is not derived from more basic assumptions about the degree of polarization.

Alesina and Tabellini (2003) build on Holmstrom's (1999) carreer concern model. Bureaucrats seek to get good reputations for competency in order to increase future pay and career opportunities, politicians do it in order enhance voters' perception of his talent so that he be reelected. The different motivations give rise to different effort levels. Alesina and Tabellini then show (among other things) that politicians tend to be best for tasks which are non-technical. They also show that time-consistency problems tends to make bureaucrats more attractive. The driving force behind the results, the career concerns is different from the one explored in the present paper.

Hanssen (2002) studies the strategic choice of mode of governance by an 
incumbent government. An incumbent government may wish to delegate decision authority to an independent agency in order to raise the cost of changing a particular policy for a future government. Hansen shows that an incumbent government is more likely to establish an independent judicary if there is higher probability that it looses the next election and the polarization of politics is larger. In this way the current government ensures that policy also in the future is guided by preferences close to its own. These results are related to the results of Persson and Svensson (1989) and Tabellini and Alesina (1990) on the strategic choice of debt by incumbent governments facing possible defeat in coming elections. Hansson shows that his prediction is confirmed on data from American states. Hanssen's aim is different from ours. He considers strategic choice of institutions by an incumbent government and not optimal choice of constitutions by the electorate. He does not consider direct democracy.

Following the lead of Barro (1973) and Ferejohn (1986) a large literature considers rent seeking politicians and the disciplining effect of elections in representative democracy, see and Persson and Tabellini (2000) for a recent overview. In this vein Aghinon et al (2002) investigate a model where an elected politician has superior information and can promote and implement reforms. The politican may be good and promote reform but may also be bad and seek to grab rents. Whatever he promotes has to pass a referendum, so a (super) majority can block it. This gives a tradeoff at the constitutional stage, a smaller the blocking majority makes it the more difficult for a bad politician to grab rents, but also more difficult to pass reforms. Aghinon et al then study the optimal choice of the size of the supermajority.

The importance of information and polarization for the functioning of representative democracy has been the subject of several papers. Schultz 
(1996) considers a model where parties are better informed about the state of the world than the electorate and commit to policies before an upcoming election. If parties' preferences are sufficiently polarized, the electorate will not learn the true state of the world and the electoral competition will lead to inefficient equilibria, since the parties' policies do not reflect the state of the world. In Schultz (2002) the electorate is supposed to have inferior information about the state of the world and the preferences of the parties. When parties cannot commit to policies before an election this leads to policy distortions as the incumbent party seeks to manipulate the beliefs of the electorate. The distortion depends on the relative imporatance of the two kinds of uncertainty: Uncertainty about preferences leads to a bias towards more centrist policies, while uncertainty about the state of the world leads to more extreme policies. Cuikerman and Tommasi (1998) consider a model with two kinds of uncertainty where parties commit to policies before an election. Under some circumstances this leads to situations where a left party most credibly can implement a rightist policy. Harrington (1993) and Letterie and Swank (1998) study a slightly different issue. In their papers the government is unsure about the state of the economy. The policies chosen then act as signals for the governments beliefs.

Kessler (2000) studies the relative merits of representative and direct democracy when voters and politicians initially are uniformed about the state of the world. She studies a one-period citizen-candidate model a la Besley-Coate (1997). There are no parties - and thus polarization of parties is not an issue - but policians are ordinary citizens who decide to run. In Kessler's model citizens can exert costly effort in order to become informed. Since ordinary voters have zero chance of being pivotal, they do not invest in information aquisition and the policy decision is uninformed under direct 
democracy. In contrast, the elected polician in representative democracy has incentives to gather information (for sufficiently low costs) and the policy choice will be informed. In this sense the model endogenizes and explains the asymmetric information Downs (1957) focussed on and I just assume in the present paper. Kessler also assumes that there is uncertainty about candidates' preferences. This induces a cost of representative democracy for the voters as the policy choice will be unpredictable. The optimal mode of governance then depends on which kind of uncertainty is the larger. Contrary to me, Kessler does not focus on polarization of parties and the policy distortion it leads to in representative democracies. Furthermore, she does not consider the effects of accountability per se, independent agencies are not considered. The cost of representative democracy in her setting exclusively stems from the uncertainty about the policians' preferences.

The remainder of the paper is organized as follows. Section 2 presents the basic model. Direct democracy is treated in section 3. Sections 4 and 5 discus independent agencies and representative democracy. The optimal mode of governance is derived in section 6. Some extensions and conclusions are provided in section 7 .

\section{Basics}

Consider a society which after a constitutional stage 0 lasts two periods, 1 and 2. In periods 1 and 2 society has to choose a policy $x$, which can be ordered on a left-right dimension, $x \in \mathbf{R}$. There are two parties: a left party $L$ and a right party $R$.

We wish to compare the expected consequences of direct and representative democracy and independent agencies evaluated at the constitutional 
stage 0 .

There are a continuum of possible states of the world, $s$, uniformly distributed on $[-\sigma, \sigma]$, where $\sigma>0$. The state of the world is the same in the two periods. Voters are not informed about the true state of the world, but they know the distribution of $s$.

Voters all have quadratic utility functions on the policy chosen, $x$, and have different bliss points. Voter $a^{\prime} s$ bliss point is $a+s$, so a voter preferes a higher policy, the higher is the state of the world, $s$. There are a continuum of voters, at date 0 , the median voter is voter 0 (with $a=0$ ) .

If $x_{1}$ is chosen in period 1 and $x_{2}$ in period 2, and the state is $s$, the total utility for voter $a$ from the two periods is

$$
-\left(x_{1}-a-s\right)^{2}-\delta\left(x_{2}-a-s\right)^{2}
$$

where the discount factor, $\delta$, fulfills $0<\delta \leq 1$.

As is clear from the utility function, the size of $\sigma$ determines whether uncertainty about the state is important of not. If $\sigma$ is very small, uncertainty is small, and it is not so important to tailor the policy correctly to the state. The opposite holds if $\sigma$ is large.

While voter 0 is the median voter at date 0 , the median voter's identity and therefore bliss point may change at future dates. This may be because preferences in the electorate change or because there is abstention in elections. The median voter at date 1 has a bliss point $\left(m_{1}+s\right)$. At time $0, m_{1}$ is unknown to the electorate, it is uniformly distributed on $[-\mu, \mu]$, where $\mu>0$. Similarly, the median voter at date two has bliss point $\left(m_{2}+s\right)$, where $m_{2}$ is uniform on $[-\mu, \mu]$. The variable $\mu$ represents the degree of uncertainty about the electorate's future preferences.

Each of the parties, $L$ or $R$, is headed by a political leader, who chooses 
the policy of the party. The political leader is partly interested in policy, and partly in power. The per period utility of the leader of party $R$ is

$$
-(x-(r+(1-\phi) s))^{2}+b,
$$

where $r+(1-\phi) s$ is the bliss point of the leader in state $s$ and $b$ represents the benefit from holding office. Just like the voters the party is interested in the sum of discounted utility from the two periods.

We assume that $0<\phi<1$. This implies that the bliss point of the median voter changes more as a function of the state than the bliss point of the politicians. The parameter $\phi$ is a measure of the stubbornness of the party. If $\phi=1$, the party is extremely stubborn, it is locked into its platform and will not change it in response to changes in $s$. If on the other hand $\phi=0$, the party is as responsive as are voters. The assumption $\phi>0$ reflects that parties to some extent are ideologically locked into their position. This may be because parties are formed of people feeling strongly for politics. It may also reflect, that the platform of a party typically depends on what is decided in conventions and programs and therefore moves more slowly. As will be clear, the stubbornness of the parties is important for the results: it implies that the median voter's vote will depend on the state of the economy, she will be a swing voter.

Party $L$ has a similar utility function, only difference is that $r$ is replaced with $l<r$. For simplicity, we consider the symmetric case where

$$
l=-r .
$$

Hence, $r$ is a measure of the polarization of parties. The larger is $r$, the more the bliss points of the two parties differ.

At the constitutional stage the future polarization of parties is unknown: $r$ is a stochastic variable uniformly distributed on $[0, \rho]$, where $\rho>0$. Thus 
$\rho$ is a measure of the expected degree of polarization, the expectation of $r$ equals $\rho / 2$. Although the degree of polarization is unknown at the constitutional stage, we assume that voters learn the preferences of the parties before possible elections in periods one and two. Clearly, one could also hold the view that voters may have difficulties in learning the preferences of politicians - in particular if the party has not held power for years. However we will assume that understanding the economy - the state of the world - is the most compliated and important issue and focus on this. For a treatment in representative democracy of the case where voters are uncertain both about the state of the world and the preferences of the parties, see Schultz (2002).

Contrary to the voters, the parties are informed about the state of the world, $s$. As discussed in the Introduction, parties are informed from experts, the governing party has direct access to the bureaucracy, the leaders of the parties are full time politicians whose job it is to gather the relevant information and take decisions. The electorate, on the other hand does not have as strong incentives to gather information.

We distinguish between three possible types of governance. Direct Democracy, $D D$, Independent Agency, $I A$, and Representative Democracy, $R D$. Under Direct Democracy the electorate in each period determines the policy, and we will assume that this implies that the median voter's preferred policy is chosen. Under Independent Agency, the voters elect a party in the start of period 1. The party governs for both periods and chooses the policy in each period. Under Representative Democracy a party is elected in the start of period 1. It chooses the first period policy, which is observed by the voters. A new election occurs in the start of period 2. The newly elected party then chooses policy for period 2 .

In the sequel we will find the expected utility from each mode of gov- 
ernance evaluated at date 0 for an arbitrary voter $a$. In this way a ranking on the different modes of governance is derived for each voter. As will be clear, the relevant trade offs are the same for all voters, regardless of their bliss point. It will therefore be the case that all voters rank the different modes the same way and it is thus meaningful to speak of an optimal mode of governance.

\section{Direct democracy}

In direct democracy, $D D$, voters in each period choose the policy preferred by the median voter without knowledge of the state of nature. The median voter $m_{1}$ 's expected utility from policy $x$ is

$$
-\int_{-\sigma}^{\sigma}\left(x-m_{1}-s\right)^{2} \frac{1}{2 \sigma} d s
$$

The optimal policy for $m_{1}$ is therefore

$$
x=m_{1} .
$$

Similarly, the median voter in period two will choose $x=m_{2}$. From the point of view of voter $a$, the expected utility at date 0 from $D D$ is therefore

$$
u^{D D}=(1+\delta) \int_{-\sigma}^{\sigma} \int_{-\mu}^{\mu}-(m-a-s)^{2} \frac{1}{2 \sigma} \frac{1}{2 \mu} d m d s,
$$

which gives

$$
u^{D D}=-(1+\delta)\left(\frac{\sigma^{2}+\mu^{2}}{3}+a^{2}\right) .
$$

We see that the more uncertainty about the state of the world and future median voters - given by the respective variances ${ }^{1}$ - the less attractive is Direct Democracy.

\footnotetext{
${ }^{1}$ Recall that when $s$ is uniform on $[-\sigma, \sigma]$, then the variance equals $\frac{\sigma^{2}}{3}$.
} 


\section{Independent Agency}

Under Independent Agency, IA, voters elect a party before date 1, who governs for both periods. The leadership of the party needs not worry about reelection and chooses its preferred policy, given knowledge of the state, regardless of the views of the median voter. The median voter $m_{1}$ elects

party $L$ if $m_{1}<0$, which occurs with probability $\frac{1}{2}$, and elects $R$ otherwise. The expected utility for voter $a$ from $I A$ is therefore

$$
\begin{aligned}
u^{I A}= & (1+\delta) \int_{-\sigma}^{\sigma} \int_{0}^{\rho}\left(-\frac{1}{2}(-r+(1-\phi) s-a-s)^{2}\right. \\
& \left.-\frac{1}{2}(r+(1-\phi) s-a-s)^{2}\right) \frac{1}{\rho} \frac{1}{2 \sigma} d r d s
\end{aligned}
$$

which yields

$$
u^{I A}=-(1+\delta)\left(\frac{\rho^{2}+\sigma^{2} \phi^{2}}{3}+a^{2}\right) .
$$

The trade-off associated with Independent Agency is clearly reflected in this expression. The larger the expected degree of polarization is, the less attractive is $I A$. The advantage associated with $I A$ is that the governing party knows the state of the world and the chosen policy therefore reflects the state of the world. The less stubborn the party is, i.e. the smaller $\phi$ is, the more will the policy reflect the state and the higher is the expected utility of the median voter.

\section{Representative Democracy}

Under representative democracy, an election is held before period one. The elected party chooses the first period policy and a new election is held after period one. The winner of the second election chooses the second period 
policy. Voters can observe the first period policy before the second election, however the utility consequences of the policy chosen in period one accrue after the election. Therefore voters are not able to infer the state of the world from the experienced utility level.

An equilibrium under Representative Democracy is a Perfect Bayesian Equilibrium of the game where voters elect a party in period 1 . The winning party observes the state of the world and then chooses the first period policy. Voters observe the policy and form posterior beliefs about the state of the world using Bayes' rule from the prior and the governing party's strategy. The first period governing party maximizes its expected utility taking into account the formation of beliefs, the voting behavior at the second election and the policy the other party will choose if the governing party looses the election.

Whether voters can infer the true state of the world or not depends on the governing party's policy strategy. As is usual in models with a continuum of states, a separating equilibrium exists under some conditions -see Mailaith (1987). In a separating equilibrium the policy chosen by the the governing party is strictly monotone in the state of the world and the voters are therefore able to infer the true state for all realizations of the state.

We will first focus on a separating equilibrium. We derive the equilibrium by solving the model backwards and first look at the second period. The second period is the last, so the parties have no reelection concerns. If elected in the second term party $R$ will choose

$$
x=r+(1-\phi) s
$$

and $L$ will choose

$$
x=-r+(1-\phi) s
$$


Hence, in a separating equilibrium, where the median voter, $m_{2}$, learns the state $s$, she prefers party $R$ if

$$
-\left(r+(1-\phi) s-m_{2}-s\right)^{2}>-\left(-r+(1-\phi) s-m_{2}-s\right)^{2},
$$

or

$$
m_{2} \geq-s \phi .
$$

As $m_{2}$ is uniformly distributed on $[-\mu, \mu]$, it follows that the probability that party $R$ wins the second election if voters learn that the state is $s, \operatorname{Pr}(R, s)$, is given by

$$
\operatorname{Pr}(R, s)=\left\{\begin{array}{ccc}
0 & \text { if } & \frac{s \phi}{\mu} \leq-1 \\
\frac{\mu-(-s \phi)}{2 \mu}=\frac{1}{2}+\frac{s \phi}{2 \mu} & \text { if } & -1<\frac{s \phi}{\mu}<1 \\
1 & \text { if } & 1 \leq \frac{s \phi}{\mu} .
\end{array}\right.
$$

We see that probability that party $R$ wins is increasing in the state.

If

$$
\frac{\sigma \phi}{\mu}<1,
$$

then $\operatorname{Pr}(R, s)$ is always given by the second line. We first focus on this case. Equation (4) makes clear that a party cannot increase the probability that it wins the election with a discrete jump by moving the policy a bit closer to the middle. The reason is that the position of the median voter is not known with certainty before the election. The payoff functions of the parties are therefore differentiable and easily tractable.

Let $s^{e}(x)$ be the state voters believe prevails, when they observe policy $x$. In a separating equilibrium, where party $R$ chooses policy $x(s)$ in the first period in state $s$, it will be the case that

$$
s^{e}(x(s))=s .
$$


Assuming that $x(s)$ is differentiable and strictly monotone, which we will verify below, we therefore have that

$$
\frac{\partial s^{e}(x)}{\partial x}=\frac{1}{\frac{\partial x(s)}{\partial s}} .
$$

Assume that party $R$ is the governing party in period one. In a separating equilibrium, party $R^{\prime} s$ total expected utility from choosing policy $x$ in period one in state $s$, if voters form expectations $s^{e}(x)$, is

$$
\begin{aligned}
& U^{R}\left(x, s, s^{e}\right)= \\
& -(x-(r+(1-\phi) s))^{2}+\operatorname{Pr}\left(R, s^{e}(x)\right) \delta(0+b)-\left(1-\operatorname{Pr}\left(R, s^{e}(x)\right)\right) \delta(2 r)^{2} .
\end{aligned}
$$

This is comprised of the first period utility from policy $x$ plus the expected second period utility. With probability $\operatorname{Pr}\left(R, s^{e}(x)\right)$ party $R$ wins the second election if it chooses $x$ today. In this case it chooses its bliss point in the second period and gets utility 0 plus the benefits from office $b$. With the complementary probability party $L$ wins the second election and chooses its bliss point giving party $R$ utility $-(2 r)^{2}$.

As we assume (5), and rational voters will have expectations $s^{e} \in[-\sigma, \sigma], \operatorname{Pr}\left(R, s^{e}\right) \in$ $[0,1]$ and we have that the expected utility for party $R$ becomes

$$
\begin{aligned}
& U^{R}\left(x, s, s^{e}\right)= \\
& -(x-(r+(1-\phi) s))^{2}+\left(\frac{1}{2}+\frac{s^{e}(x) \phi}{2 \mu}\right) b-\delta\left(1-\left(\frac{1}{2}+\frac{s^{e}(x) \phi}{2 \mu}\right)\right)(2 r)^{2} .
\end{aligned}
$$

Assuming that the second order condition is fulfilled, which we will verify below, party $R^{\prime} s$ optimal choice of policy in period 1 is therefore given by the first order condition

$$
\frac{d U^{R}\left(x, s, s^{e}\right)}{d x}=0
$$


which gives

$$
-2(x(s)-r-(1-\phi) s)+\delta \frac{\partial s^{e}}{\partial x}(x(s)) \frac{\phi}{2 \mu}\left((2 r)^{2}+b\right)=0 .
$$

Using (6) yields

$$
-2(x(s)-r-(1-\phi) s)+\delta \frac{2}{\frac{\partial x(s)}{\partial s}} \frac{\phi}{\mu}\left(r^{2}+\frac{b}{2}\right)=0,
$$

which we rewrite

$$
x(s)=r+(1-\phi) s+\frac{1}{\frac{\partial x(s)}{\partial s}} \frac{\delta \phi}{\mu}\left(r^{2}+\frac{b}{2}\right) .
$$

This is a first order differential equation with solution

$$
x(s)=r+(1-\phi) s+\frac{\delta \phi}{1-\phi} \frac{1}{\mu}\left(r^{2}+\frac{b}{2}\right) .
$$

We see that party $R$ distorts its policy upwards above its bliss point $r+$ $(1-\phi) s$ and that the distortion is larger, the larger is the degree of polarization, the pure power benefit, $b$, the density of the distribution of the median voter (which equals $\frac{1}{2 \mu}$ ), and the degree of stubbornness. More polarization and stubbornness, makes party $L^{\prime} s$ policy worse from the point of view of party $R$. It therefore becomes more eager to win the election, and since a higher $x$ improves $R^{\prime} s$ chance of winning it distorts its policy further up. Recall that the probability party $R$ wins equals $\left(\frac{1}{2}+\frac{s^{e}(x) \phi}{2 \mu}\right)$. Hence the higher is $s^{e}(x)$ the larger is the probability of winning. In the separating equilibrium, $s^{e}(x)=x^{-1}(x(s))$. Using (8) this gives

$$
s^{e}(x)=\frac{x-r-\frac{\delta \phi}{1-\phi} \frac{1}{\mu}\left(r^{2}+\frac{b}{2}\right)}{1-\phi},
$$

which is strictly increasing in $x$. A higher $x$ therefore improves party $R^{\prime} s$ chance of winning the election. In equilibrium, the party trades off the first 
period loss from having a too high policy with the second period gain from winning the election with a higher probability. A high density of the median voter distribution implies that many votes are gained from changing $s^{e}$ a little. A high $\frac{1}{\mu}$ therefore makes the policy more distorted. Similarly, a high $\delta$ makes tomorrow more important and the incentive to distort the policy today is increased.

In equilibrium, voters are not fooled by party $R^{\prime} s$ attempt to manipulate their beliefs, they perfectly learn the state. The party nevertheless has to distort its policy upwards, since had it not, the voters would have expected the state was lower and party $R$ had won the second election with a lower probability.

Incidentally, equation (9) shows that $s^{e}(\cdot)$ is a differentiable function as claimed. Since it is linear in $x$, it is readily seen that the second order condition for maximum of $U^{R}\left(x, s, s^{e}(x)\right)$ is fulfilled as claimed above.

If party $L$ wins the first election, everything is as above except that party $L$ chooses policy

$$
x_{l}(s)=-r+(1-\phi) s-\frac{\delta \phi}{1-\phi} \frac{1}{\mu}\left(r^{2}+\frac{b}{2}\right) .
$$

Party $L$ distorts the policy downwards. 
The expected utility at date 0 for voter $a$ from $R D$ is therefore

$$
\begin{gathered}
u^{R D}= \\
\int_{0}^{\rho} \int_{-\sigma}^{\sigma} \frac{1}{\rho} \frac{1}{2 \sigma} \times \\
\left(-\frac{1}{2}\left(-r+(1-\phi) s-\frac{\delta \phi}{1-\phi} \frac{1}{\mu}\left(r^{2}+\frac{b}{2}\right)-a-s\right)^{2}\right. \\
-\frac{1}{2}\left(r+(1-\phi) s+\frac{\delta \phi}{1-\phi} \frac{1}{\mu}\left(r^{2}+\frac{b}{2}\right)-a-s\right)^{2} \\
-\delta\left(\left(\frac{1}{2}+\frac{s \phi}{2 \mu}\right)(r+(1-\phi) s-a-s)^{2}\right. \\
\left.\left.\quad-\left(1-\left(\frac{1}{2}+\frac{s \phi}{2 \mu}\right)\right)(-r+(1-\phi) s-a-s)^{2}\right)\right) d s d r,
\end{gathered}
$$

which gives

$$
\begin{aligned}
u^{R D}= & -\underbrace{(1+\delta)\left(\frac{\rho^{2}+\sigma^{2} \phi^{2}}{3}+a^{2}\right)}_{=u^{I A}} \\
& -\underbrace{\rho^{2} \frac{\rho}{\mu}\left(\frac{\delta \phi}{2(1-\phi)}+\frac{\rho}{\mu} \frac{\delta^{2} \phi^{2}}{5(1-\phi)^{2}}\right)+c(b)}_{\text {loss from 1.st period distortion }}+\underbrace{\delta \frac{\rho \frac{\sigma^{2} \phi^{2}}{\mu}}{3}}_{\text {gain from accountability }} .
\end{aligned}
$$

where

$$
c(b) \equiv-\left(\frac{\rho}{\mu} \frac{\delta \phi}{2(1-\phi)}+\frac{(\delta \phi)^{2}}{3(1-\phi)^{2}} \frac{\rho^{2}}{\mu^{2}}+\frac{b(\delta \phi)^{2}}{4(1-\phi)^{2} \mu^{2}}\right) b<0
$$

The first term in (10) equals $u^{I A}$, this is the expected utility of voter $a$, when the same party chooses its bliss point in both periods. The second term reflects the loss to voter $a$, due to the policy distortion in the first period. The third term reflects the gains from accountability. This is the expected value of having the opportunity to choose the other party, should the state of the world make this party most favorable to voter $a$. 
The term $c(b)$ stems from the extra distortion the governing party makes because it would like to enjoy the benefits from power, $b$, in the next period. We see that the higher the benefits from office, the lower is the expected utility for the voters from representative democracy. Notice that $c(0)=0$.

The loss from the first period distortion is clearly larger, the larger the distortion and therefore larger the larger is $\rho, \phi, \frac{1}{\mu}$ and $\delta$ as discussed in relation to the policy. The gain from accountability increases in the same variables as well as the uncertainty about the state as reflected in $\sigma$. When $\sigma$ is high, the gain from exchanging government in the second period is potentially high. This is even more important the more stubborn the parties are and the larger is polarization. More uncertainty about the future median voter's blisspoint - a higher $\mu$ - makes accountability less valueable, since it introduces uncertainty about the electoral outcome in the second election.

\subsection{A semi-separating equilibrium}

When condition (5) is not fulfilled the above analysis modifies when $s$ is low and high. For $s \in\left[-\frac{\mu}{\phi}, \frac{\mu}{\phi}\right]$, the probability that party $R$ wins is still given by the second line in (4) and the analysis is unchanged. For $s \in\left[-\sigma,-\frac{\mu}{\phi}\right]$ party $R$ looses the election for sure in a potential separating equilibrium. In this case party $R$ has no incentive to distort its policy, and it chooses its bliss point. This implies that voters still learn the state for $s \in\left[-\sigma,-\frac{\mu}{\phi}\right]$ and the equilibrium will be separating in this range. For $s \in\left[\frac{\mu}{\phi}, \sigma\right]$ party $R$ wins for sure if voters learn that indeed $s$ belongs to this range. If voters believe this, party $R$ cannot increase the probability that it wins by choosing a higher $x$. Hence, the incentive to distort $x$ further disappears. To reduce the length of the formulas, we let $b=0$ in the following. If party $R$ is the governing party in period one, the following will be the "most separating" semi-separating 
equilibrium

$$
x(s)=\left\{\begin{array}{clc}
r+(1-\phi) s & \text { for } & -\sigma \leq s \leq-\frac{\mu}{\phi} \\
r+(1-\phi) s+\frac{\delta \phi}{1-\phi} \frac{1}{\mu} r^{2} & \text { for } & -\frac{\mu}{\phi} \leq s \leq \frac{\mu}{\phi} \\
r+(1-\phi) \frac{\mu}{\phi}+\frac{\delta \phi}{1-\phi} \frac{1}{\mu} r^{2} & \text { for } & \frac{\mu}{\phi} \leq s \leq \min \left[\frac{\mu}{\phi}+\frac{\delta \phi}{(1-\phi)^{2}} \frac{r^{2}}{\mu}, \sigma\right] \\
r+(1-\phi) s & \text { for } & \frac{\mu}{\phi}+\frac{\delta \phi}{(1-\phi)^{2}} \frac{1}{\mu} r^{2} \leq s \leq \sigma \text { if the interval exists }
\end{array}\right.
$$

The beliefs of the voters are derived from this strategy using Bayes' rule and are given by

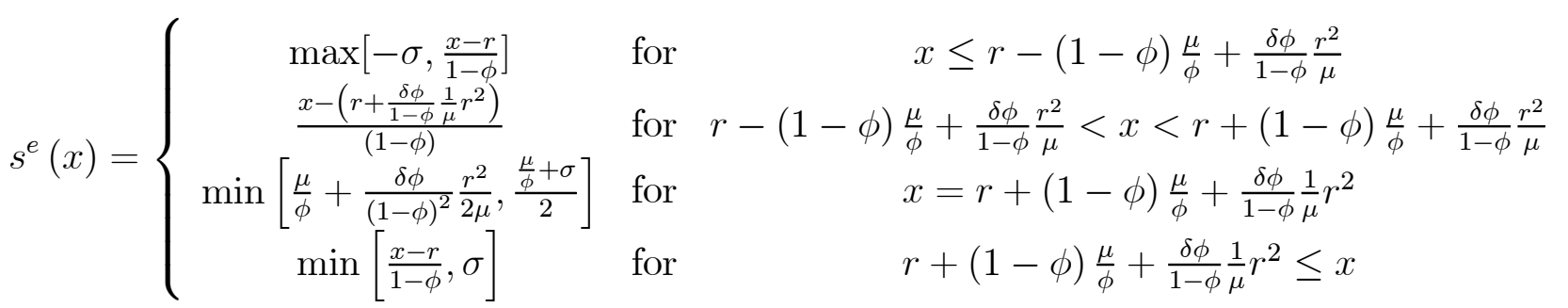

Given these beliefs and the results of the previous section it is easy to check that the strategy is indeed optimal for party $R$.

The cut-off point $s^{\prime}=\frac{\mu}{\phi}+\frac{\delta \phi}{(1-\phi)^{2}} \frac{1}{\mu} r^{2}$, is determined by the condition that party $R$ 's bliss point in state $s^{\prime}$ equals $r+(1-\phi) \frac{\mu}{\phi}+\frac{\delta \phi}{1-\phi} \frac{1}{\mu} r^{2}$.

The expression for voter $a^{\prime} s$ expected utility becomes $\int_{0}^{\rho} \frac{1}{\rho} \Gamma(r) d r$, where 
$\Gamma(r)$ is given by

$$
\begin{aligned}
& -\int_{-\sigma}^{-\frac{\mu}{\phi}} \frac{1}{2 \sigma}\left((r+(1-\phi) s-a-s)^{2}+\delta(-r+(1-\phi) s-a-s)^{2}\right) d s \\
& -\int_{-\frac{\mu}{\phi}}^{\frac{\mu}{\phi}} \frac{1}{2 \sigma}\left(r+(1-\phi) s+\frac{\phi}{1-\phi} \frac{1}{\mu} r^{2}-a-s\right)^{2} \\
& -\delta\left(\frac{1}{2}+\frac{s \phi}{2 \mu}\right)(r+(1-\phi) s-a-s)^{2} \\
& +\delta\left(1-\left(\frac{1}{2}+\frac{s \phi}{2 \mu}\right)\right)(-r+(1-\phi) s-a-s)^{2} d s \\
& -\int_{\frac{\mu}{\phi}}^{\frac{\mu}{\phi}\left(1+\frac{r^{2}}{(1-\phi)^{2}}\right)} \frac{1}{2 \sigma}\left(r+(1-\phi) \frac{\mu}{\phi}+\frac{\phi}{1-\phi} \frac{1}{\mu} r^{2}-a-s\right)^{2}+\delta(r+(1-\phi) s-a-s)^{2} d s \\
& -\int_{\frac{\mu}{\phi}\left(1+\frac{r^{2}}{(1-\phi)^{2}}\right)}^{\sigma} \frac{1}{2 \sigma}(r+(1-\phi) s-a-s)^{2}+\delta(r+(1-\phi) s-a-s)^{2} d s
\end{aligned}
$$

which does not simplify nicely. However, the effect should be clear. Compared with the fully separating equilibrium of the previous section, the distortion is smaller. For low values of $s, s \in\left[-\sigma,-\frac{\mu}{\phi}\right]$, there is no distortion in the first period and a certain change of government in the next period, for high values of $s, s \in\left[\frac{\mu}{\phi}, \sigma\right]$, the distortion is smaller. This tends to make $R D$ more favorable than if there were distortions for all $s$.

In the following we concentrate on the case where (5) is fulfilled and the equilibrium fully separating under $R D$.

\section{The constitutional choice}

We now consider the constitutional choice at date 0 . Any voter prefers the mode of governance which gives the highest expected utility. In the formulas for the expected utilities for each mode of governance, a voter's idiosyncratic part of her bliss point, $a$, enters only once in the term $-(1+\delta) a^{2}$. Hence 
the ranking in expected utility of the three modes of governance is the same for all voters $a$. The reason is simple, the three modes of governance are not biased in any particular way on the left-right dimension. Hence, the relevant trade offs between the three modes are the same for all voters.

We proceed by comparing the modes pairwise.

Using (2) and (3), we get that $D D$ is preferred to $I A$ iff

$$
\sigma^{2} \leq \frac{\rho^{2}-\mu^{2}}{1-\phi^{2}}
$$

Direct democracy has the disadvantage that the state of the world is unknown to the decision maker, the future median voter, and the position of this median voter is also uncertain. The larger are the uncertainties about this, the less attractive is $D D$. Independent Agency ensures that the choice of policy is informed. This advantage is larger the less stubborn are the parties. Furthermore polarization makes independent agency less attractive.

Using (10) and (3), we get that $R D$ is better than $I A$ iff

$$
\delta \frac{\rho}{\mu} \frac{\sigma^{2} \phi^{2}}{3} \geq \rho^{2} \frac{\rho}{\mu}\left(\frac{\delta \phi}{2(1-\phi)}+\frac{\rho}{\mu} \frac{\delta^{2} \phi^{2}}{5(1-\phi)^{2}}\right)+c(b)
$$

that is when the gain from accountability exceeds the utility cost of the distorted first period policy.

Rewriting, we get

$$
\sigma^{2} \geq 3 \rho^{2}\left(\frac{1}{2 \phi(1-\phi)}+\frac{\rho}{\mu} \frac{\delta}{5(1-\phi)^{2}}\right)+\frac{3 \mu}{\rho \delta \phi^{2}} c(b)
$$

Hence the larger the variance of the state, the more attractive is $R D$. This makes accountability, the option of replacing the party in power, more valuable. Differentiating the right hand side wrt $\rho$ shows it is increasing in $\rho$. When $\rho$ increases, then the first period policies become more distorted under $R D$ and this tends to make $I A$ more attractive. A higher discount factor 
increases the option value from the possibility of replacing the government in the future, but it also increases the governing party's incentives to distort the first period policy. The latter effect dominates, therefore a higher $\delta$ tends to make $R D$ less attractive. The same is true for the density of the median voter $\frac{1}{2 \mu}$. The increase in the distortion of policy dominates the effect that the government is more often replaced. The degree of stubbornness enters non-monotonically on the right hand side.

Lemma 1 For all $\rho, \phi, \mu, \delta$ fulfilling $0<\phi<1$ and $\rho, \mu, \delta>0$

$$
\frac{\rho^{2}-\mu^{2}}{1-\phi^{2}} \leq 3 \rho^{2}\left(\frac{1}{2 \phi(1-\phi)}+\frac{\rho}{\mu} \frac{\delta}{5(1-\phi)^{2}}\right)
$$

Proof: Multiplying on both sides with $1-\phi^{2}$ and reducing a bit gives

$$
\rho^{2}-\mu^{2} \leq 3 \rho^{2}\left(\frac{1}{2} \frac{1+\phi}{\phi}+\frac{\rho}{\mu} \frac{\delta\left(1-\phi^{2}\right)}{5(1-\phi)^{2}}\right)
$$

which clearly true as $0<\phi<1$, and $\rho, \mu, \delta>0 \square$

Combining the pairwise comparisons above and using Lemma 1 , directly gives

Theorem 2 Assume that condition (5) holds. All voters find at date 0 that

1. $D D$ is the preferred mode of governance if the uncertainty about the state of nature is low, i.e. if

$$
\sigma^{2} \leq \frac{\rho^{2}-\mu^{2}}{1-\phi^{2}}
$$

2. IA is the preferred mode of governance if the uncertainty about the state of nature is intermediate, i.e. if

$$
\frac{\rho^{2}-\mu^{2}}{1-\phi^{2}} \leq \sigma^{2} \leq 3 \rho^{2}\left(\frac{1}{2 \phi(1-\phi)}+\frac{\rho}{\mu} \frac{\delta}{5(1-\phi)^{2}}\right)+\frac{3 \mu}{\rho \delta \phi^{2}} c(b)
$$


3. $R D$ is the preferred mode of governance if the uncertainty about the state of nature is high, i.e. if

$$
3 \rho^{2}\left(\frac{1}{2 \phi(1-\phi)}+\frac{\rho}{\mu} \frac{\delta}{5(1-\phi)^{2}}\right)+\frac{3 \mu}{\rho \delta \phi^{2}} c(b) \leq \sigma^{2}
$$

A higher degree of expected polarization of parties, $\rho$, increase all the above cut-off points.

Direct Democracy is best when the uncertainty about the state is low. The informational advantage from delegating the policy decision to an informed politician becomes small in this case. A higher degree of polarization of parties also makes direct democracy more attractive. The cut-off point between $I A$ and $R D$ is also increased when the degree of polarization increases. The increased polarization makes $R D$ less attractive, since the policy distortions in the first period increase. An increase in the degree of stubbornness, makes direct democracy more attractive. The effect on the boundary between $I A$ and $R D$ depends on the exact parameter values as it tends to make both modes less attractive. Finally an increase in the density of the future median voters makes $D D$ more attractive- this reduces the uncertainty about the future policies chosen under $D D$. An increase in $\frac{1}{\mu}$ also makes $R D$ less attractive relative to $I A$.

Figure 1 below illustrates the Theorem for $\phi=\frac{1}{4}, \delta=.9, b=0$ and $\mu=1$. For these parameter values condition (5) becomes $\sigma^{2} \leq 16$.

\section{Concluding remarks}

This paper has studied the trade off implied by the polarization of politics and the asymmetric information between the politicians and the electorate. 


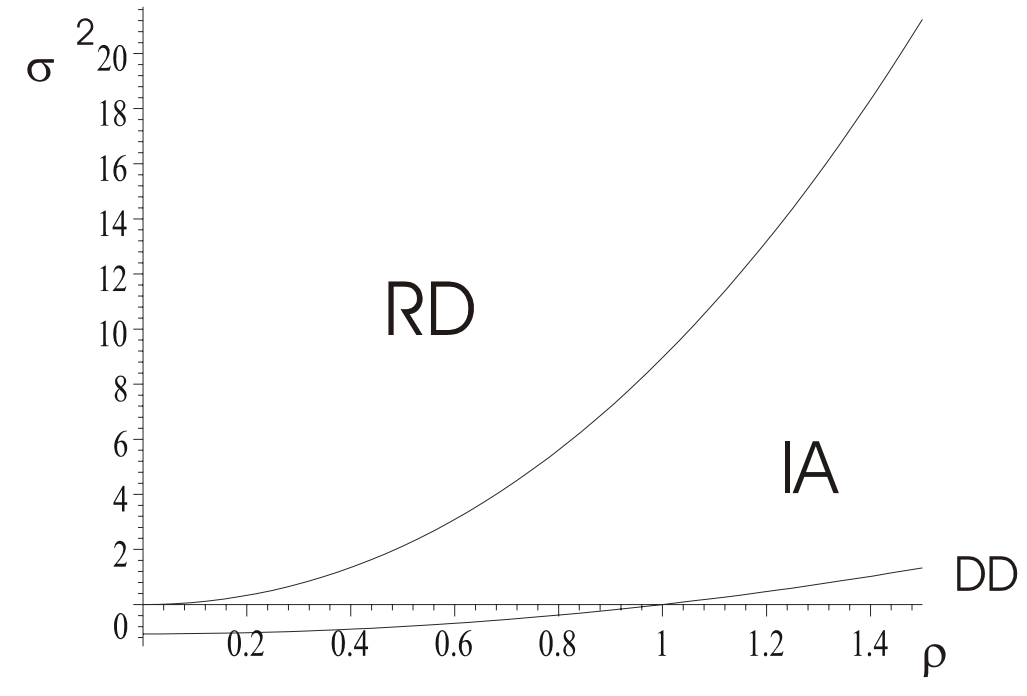

Figure 1:

The main message of this paper is that the degree of polarization of politics and the uncertainty about the state of nature are important determinants for which mode of governance is optimal. The more polarized is politics and the less is the uncertainty about the state of the world, the more attractive is direct democracy. The less polarization and more uncertainty about the state of the world, the more attractive representative democracy. For intermediate values independent agencies may be the optimal choice of mode of governance. For high degrees of polarization, the incumbent government distorts policy and this induces a cost which overshadows the benefit from representative democracy, the option value attached to the fact that the voters may replace the government. An important extension of the model will be to include the role of an independent press. Ceteris paribus, one will expect that this will make representative democracy more attractive from the point of the voters, since the governments influence on voters' beliefs will be 
reduced, this should reduce the tendency to distort the policy.

\section{References}

[1] Aghinon P., A. Alesina, and F. Trebbi (2002), Endogeneous Political Institutions, Harvard Institute of Economic Research, Discussion Paper 1957

[2] Barro, R. (1973), The Control of Politicians, An Economic Model, Public Choice, 14, 19-42

[3] Bartels, L.M. (1996), Uninformed Voters: Information Effects in Presidential Elections, American Journal of Political Science, 40 (1), 194-230

[4] Besley, T. and S. Coate (1997), An Economic Model of Representative Democracy, Quarterly Journal of Economics, 112, 85-114

[5] Besley, T. and S. Coate (2000a), Elected versus Appointed Regulators: Theory and Evidence, mimeo, LSE

[6] Besley, T. and S. Coate (2000b), Non-Majoritan Policy Outcomes and the Role of Citizens' Initiatives, mimeo, LSE

[7] Ferejohn, J. (1986), Incumbent Performance and Electoral Control, Public Choice, 50, 5-26

[8] Hanssen, A. (2002), Is there an optimal level of judicial independence?, mimeo, Montana State University

[9] Harrington, J.E. (1993), Economic Policy, Economic Performance and Elections, American Economic Review, (83), March, 27-42 
[10] Kessler, A. (2000), Representative versus Direct Democracy: The Role of Informational Asymmetries, Bonn Econ Discussion Papers, 18/2000

[11] Letterie, W. and O. Swank (1998), Economic Policy, Model Uncertainty and Elections, Economics and Politics, 10, (1), 85-103

[12] Mailath, G. (1987), Incentive Compatibility in Signalling Games with a Continuum of Types, Econometrica, 55, (6), 1349-1365

[13] Maskin, E. and J. Tirole (2001), The Politician and the Judge, Accountability in Government, mimeo, Princeton University and Université de Toulouse.

[14] Matsusaka, J. (1992), Economics of Direct Legislation, Quarterly Journal of Economics, 107, 541-71

[15] Persson, T. and L.E.O. Svensson (1989), Why a stubborn conservative would run a Deficit: Policy iwth Time-Inconsistent Preferences, Quarterly Journal of Econoimcs, 104, 325-45

[16] Persson, T. and G. Tabellini (2000), Political Economics, Explaining Economic Policy, Cambridge, MIT Press

[17] Schultz, C. (1996), Polarization and Inefficient Policies, Review of Economic Studies, 63, (2), 331-344

[18] Schultz, C. (2002), Policy Biases with Voters' Uncertainty about the Economy and the Government. European Economic Review, 46, 487506

Tabellini, G. and A. Alesina (1990), Voting on the Budget Deficit, American Economic Review, 80, 37-49 